\title{
Introducing the Qualitative Pretest Interview (QPI) for questionnaire development
}

\author{
Buschle, Christina ${ }^{1}$, Reiter, Herwig ${ }^{2}$ and Bethmann, Arne ${ }^{3}$
}

10 July 2020

\section{Summary}

Cognitive interviews have become one of the most important pretest methods in the development and evaluation of questionnaires. Different techniques such as thinking aloud or various probing approaches analyse the comprehensibility and interpretation of questions, uncover difficulties of respondents in answering questionnaires as well as underlying causes. A desideratum of this approach is the methodological framing for which we make a proposal in this article. Direct research interaction in pretest situations can be regarded as an act of understanding others in the sense of qualitativeinterpretive social research. On this basis, we discuss the advantage of methodically integrated communication strategies of two established qualitative survey methods - the problem-centred interview and the discursive interview - for the development of a distinct pretest interview approach. It adopts the techniques of the cognitive interview and expands them by the essentially social character of processes of clarifying comprehension. We introduce the term Qualitative Pretest Interview (QPI) in order to avoid the possible narrowing of the understanding of pretest procedures to the problem of ambiguous cognitions. Finally, we reflect on the potential of this approach for standardized survey research.

\section{Introduction}

Surveys require researchers to have a precise idea of the theoretical constructs they want to investigate and of their presumed connectedness. Furthermore, it is necessary to measure these constructs validly by means of a questionnaire. In other words, good survey research depends on asking the right questions; it is the only way to ensure that the information collected from respondents is suitable for providing good answers to our research questions. In this article, we will essentially deal with a specific issue of valid measurement: How can we formulate questions in such a way that they are understood adequately and produce answers that we can consider valid? The paper is intended as a contribution to a pragmatic-professional consideration and integration of qualitative-interpretive perspectives in the preparation of standardised surveys.

The work of Tourangeau and colleagues on the "Cognitive Aspects of Survey Methodology" (CASM, see Tourangeau 1984) is of importance for understanding how individuals act and react in surveys. The "Response Process Model" suggests distinguishing between four steps regarding the respondents' way

\footnotetext{
${ }^{1}$ IUBH University of Applied Sciences Distance Learning, Department of Adult Education, Bad Reichenhall, Germany, c.buschle@iubh-fernstudium.de

${ }^{2}$ German Youth Institute, Department of Social Monitoring and Methodology, Munich, Germany, reiter@dji.de

${ }^{3}$ Technical University of Munich (Chair for the Economics of Aging), Munich Center for the Economics of Aging (MEA), Max Planck Institute for Social Law and Social Policy, Munich, Germany, 
of processing information and arriving at (the choice of) an answer: comprehension, retrieval, judgement, and response (Tourangeau et al. 2000). The model considers the characteristics of the questionnaire (e.g. comprehensibility) and of the respondents (e.g. memory) as well as the peculiarities of the interview situation including interviewers that may be present (e.g. regarding dealing with sensitive questions). There is by now extensive literature on all of these aspects and possible sources of survey measurement errors that provide suggestions for improving standardised questionnaires (e.g. Bradburn et al. 2004; Faulbaum et al. 2009; Groves et al. 2009; Porst 2014; Schnell 2012; Wolf et al. 2016).

Yet general recommendations like these are not able to anticipate the diversity and complexity of standardised surveys. For each study, the practical circumstances of the interview situation can be quite different depending on the specific research question, the target population, the mode of data collection, etc. Therefore, survey methods research recommends the extensive use of pretestprocedures to review and improve instruments before they are used in the main survey (cf. e.g. Bradburn et al. 2004; Schnell 2012). Pilot and pretest-studies are an integral part of professionally conducted studies; yet their scope and purpose often differ. Some pretesting procedures deal with the quality of the survey instruments itself in addition to testing organizational aspects and fieldwork procedures (e.g. deployment of interviewers, IT functionality, etc.). A common approach is to conduct a limited number of pretest interviews and then perform an evaluation of this small dataset based on statistical criteria, such as the accumulation of non-response or unexpected distributions across response categories. More complex tests might also involve e.g. psychometric properties of scales or measurement invariance tests.

A non-statistical aspect of developing surveys discussed already in the 1940s concerns the question, whether open forms of interaction between interviewer and respondent could altogether provide more valid answers to research questions (Beatty 1995). Although standardised procedures dominate primary data collection due to efficiency issues and concerns about interviewer bias, the use of open techniques and the benefits of reactivity for the validation of survey instruments are largely undisputed. In some studies, especially during questionnaire development, in-depth analyses of individual interviews supplement the above-mentioned statistical pretests and evaluations. Often inspired by the four-step Response-Process-Model of Tourangeau et al. (2000) these analyses want to comprehend the respondents' process of answering in order to identify problems with the instrument. In recent decades the method of cognitive pretesting was developed in addition to the observation and coding of respondents' reactions (e.g. requests to interviewers, or hesitation). It is based on variations of 'thinking aloud' during the process of answering the questionnaire, and on trained interviewers asking follow-up questions ('probing') in order to collect detailed information on problems in the answering process (e.g. Lenzner et al. 2016; Willis 2005, 2015).

Against this background, the following chapter deals with the foundations and practical aspects of the particular Cognitive Interview developed by Willis since the 1990s. A desideratum and - from our point of view - underdeveloped aspect of this method is the methodological reflection of the process of interaction and comprehension between respondents and researchers, as described, for instance, by Suchman and Jordan (1990). Therefore, the third chapter discusses the extent to which purpose and practice of the Cognitive Interview share commonalities with qualitative social research in general and qualitative interview research in particular. We suggest regarding the direct research interaction between respondents and researchers especially in pretest situations as a communication process and thus as an act of intersubjective understanding (Fremdverstehen). We propose a novel methodological framing for the available techniques of the Cognitive Interview that we supplement and expand based on two established qualitative interview methods, namely the Problem-centred Interview (Witzel und Reiter 2012; Reiter and Witzel 2019) and the Discursive Interview (Ullrich 1999; 2019). The fourth 
section introduces and discusses communication strategies of these two techniques regarding their usefulness for the development of an alternative pretest interview approach that we call 'Qualitative Pretest Interview' (QPI). Finally, we discuss this proposal and reflect on its potential for standardized survey research.

\section{Cognitive Interview: background and approach}

Since the 1980s cognitive techniques have been an important part of the process of developing, testing, reviewing, and evaluating standardised questionnaires and individual survey questions. With their origin in the tradition of cognitive psychology (Ericsson and Simon 1980) they help identify, together with participants, problems with the questionnaire and correct them if necessary. Beatty and Willis (2007) define Cognitive Interviews accordingly as "the administration of draft survey questions while collecting verbal information about the survey response or to help determine whether the question is generating the information that its author intends" (ibid., p. 287). Especially in Englishspeaking countries, the Cognitive Interview is considered part of the qualitative research tradition and implemented by qualitative researchers (Miller et al. 2014, p. 2). Its application is broadly recognised in standardised survey research, it is regularly used in questionnaire development and continually enhanced (Conrad and Blair 2009; Miller et al. 2014; Collins 2003, 2015a). Gordon B. Willis (e.g. 1994, $1999,2005,2015,2017$ ) is regarded as one of the pioneers of cognitive interviewing and continues to advocate and develop it.

Willis (1999: 3) roughly distinguishes between two "major sub-types of cognitive interviewing", i.e. "thinking aloud" and "verbal probing" (Willis 2005; Beatty and Willis 2007). These alternative paradigms are differentiated according to the extent of the involvement of the interviewer. Thinkingaloud initially limits the activities of the interviewer to maintaining the flow of thoughts of the participants. Verbal probing, on the other hand, is somewhat more complex; Willis (2005, p. 47) writes: "Assuming a face-to-face interview, the interviewer asks the target question and the subject answers it, but the interviewer then follows up (...) by probing for other specific information relevant to the question or to the specific answer given." The follow-up activities of the interviewer depend on the behaviour of the participants as well as their cognitive abilities and age. Willis argues for a careful selection of probes and explorations in order not to neglect research interests in favour of an exaggerated focus on the interests of the participants that may not correspond to the interests of the researcher. Caution is necessary, however, in order not to take control of the interview and dominate the entire conversation (Beatty and Willis 2007).

Nonetheless, the interviewer or the researcher must decide, in advance or during the interview, what kind of follow-up techniques seem appropriate. Willis $(2005 ; 2015)$ provides a variety of probing options for this purpose, like "emergent probes", "spontaneous probes", "anticipated probes", "conditional probes", "evaluative probes" or "hypothetical probes" (Beatty and Willis 2007; Willis and Artino 2013; Pan et al. 2014 quoted in Willis 2015, p. 37). These cognitive probes can be combined, and so can the two basic techniques: "In practice, think-aloud and verbal probing actually fit together" (Willis 2005, p. 57). The application of different ways of probing and their combination in the right way, however, is described as difficult (e.g. Presser et al. 2004; Beatty and Willis 2007).

All these diverse probing techniques serve specific purposes in the context of the Cognitive Interview; their application is described and illustrated extensively in the related literature (cf. Willis 2005, 2015; Miller et al. 2014; Collins 2003, 2015a) ${ }^{4}$. What is lacking, especially when focusing on the two main

\footnotetext{
${ }^{4}$ In this paper we focus mainly on the anglo-saxon literature on Cognitive Interviewing as a backdrop for our methodological discussion. There is also a practice-oriented body of literature in the German-speaking countries (see e.g. Prüfer and Rexroth 2000, 2005; Faulbaum et al. 2009; Porst 2014; Lenzner et al. 2016), which we summarize and discuss in Bethmann et al. 2019.
} 
strategies of verbal probing and thinking-aloud, is a common methodological frame that could integrate them. Against this background, the following chapters pursue two objectives. First, we conceptualise direct research interactions in pretest situations as acts of intersubjective understanding (Fremdverstehen). Second, we refer to methodically integrated communication strategies of two qualitative interviewing methods that are well-established in German-speaking social research. We then use these communication strategies to develop an alternative pretest-interview approach that integrates the original techniques of the Cognitive Interview - i.e. thinking-aloud and the diverse selection of probes - by emphasizing the essentially social character of the process of jointly producing comprehension. To avoid a narrow understanding of pretest procedures as being confined to the problem of potentially ambiguous cognitions, we introduce the term Qualitative Pretest Interview $(\mathrm{QPI})^{5}$ for our alternative approach.

\section{Intersubjective understanding in cognitive and qualitative interviews}

The 'cognitive turn' that gained momentum in US survey research in the 1980s is ongoing and moves cognitive methods originally derived from psychology ever closer to qualitative social research. For instance, Beatty and Willis (2007, p. 299) recommend cognitive interviewers to adopt suggestions and "some guidance" from the literature on qualitative interview procedures. Moreover, a more recent edited volume on cognitive interviewing by Miller et al. (2014) explicitly tries to build a bridge between the concepts of cognition and interpretation - the volume is praised by Willis (2014, p. xiii) in the preface as: "the furthest point in the evolution of cognitive interviewing as a mature expression of qualitative research". Even if the foundations of the interpretive approach therein (still) remain rudimentary (Chepp and Gray 2014), central concepts such as 'narration' and 'understanding' are at least incorporated into the discourse on the improvement of standardised survey instruments. Already at the beginning of the 1990s, there was a prominent debate about the limits of survey interviews following a contribution by two anthropologists (Suchman and Jordan 1990) regarding the essentially interactive character of standardised face-to-face interviews and the associated problem of measurement error (Platt 2001). The article published in the Journal of the American Statistical Association and the subsequent appreciative comments by statisticians and proponents of quantitative social research revolve around the central notion of understanding and the significance of formulations and statements. Also, this line of discussion is ongoing in the English-language literature (Schaeffer and Maynard 2001; Gobo and Mauceri 2014; Gabarski et al. 2016).

Finally, boundaries between the notions of 'cognitive' and 'qualitative' are blurring when it comes to the practical implementation of the Cognitive Interview. Willis's (1999) earlier comments focus on cognitive aspects in the narrow sense, since he was primarily concerned with the 'transfer of information': "We use cognitive interviewing techniques to study the manner in which targeted audiences understand, mentally process, and respond to the materials we present" (Willis 2005, p. 3). In his older recommendations on the implementation of the Cognitive Interview, he neglects the possible relevance of qualitative-empirical aspects. In the meantime, he underlines that "the method in essence represents a form of qualitative inquiry" (Willis 2015, p. 1). More recent textbooks corroborate the many similarities of implementing cognitive and qualitative interviews. Collins (2015b, p. 20), for example, writes unequivocally: "Cognitive interviews are qualitative in nature, involving an in-depth interviewing approach and typically small, purposive samples." Gray (2015, p. 126f.) adds that cognitive interviewers require a mixed-methods-skills profile and are also equipped with competences in standardised interviewing. He writes, "In many ways a cognitive interviewer requires the same skills

\footnotetext{
${ }^{5}$ The label 'qualitative' is chosen to underline the fact that successful intersubjective understanding is a social (i.e. interactive) as much as a cognitive achievement and cannot be studied in a standardized way. Especially the German-language social sciences still suffer from a rather strict separation of qualitative and quantitative camps that is rarely overcome for the sake of improving research.
} 
as a qualitative interviewer but we would argue that there is also a need for the cognitive interviewer to be familiar with the conventions and practices of survey interviewers".

In general, the Anglo-American methodology discourse seems more open to pragmatic debates searching for ways of improving the validity of standardised surveys beyond exclusively quantitative approaches. In contrast, the German social science context still suffers from a hiatus between qualitative and quantitative camps that is only tentatively overcome by few rogue crossover researchers and, slowly, by a small mixed methods research community (Weischer 2018; Ploder 2018). Among proponents of standardised research, the recognition of the benefits of pretesting surveys, and especially the use of Cls, is hardly contested (cf. Bethmann et al. 2019). It even resulted in important social research infra structure institutions like GESIS (Leibniz Institute for the Social Sciences) offering related services. ${ }^{6}$ However, methodologically, so far Cls are still considered by both quantitative and qualitative researchers as being part of the tradition of standardised research alone. Accordingly, the current praxis of cognitive pretest-interviewing in Germany usually does not consider standards of qualitative research, and much less does it involve researchers focussing on qualitative methods.

Already four decades ago, Kohli (1978) contributed a fundamental discussion of differences and similarities between unstructured and standardised interviews. He argues that situativity, interactivity and reactivity characterise both open and closed interview techniques. The validity of all kinds of interview data crucially depends on the equal understanding of the meaning communicated in (preformulated) questions and answers by all participants - i.e. at least for researchers, interviewers, and respondents. In the direction of standardised procedures, Kohli (1978, p. 9; own translation) finally writes: "Communication always means intersubjective understanding (albeit to varying degrees)". The challenge of understanding inevitably vague and 'indexical expressions' (Garfinkel 1984/1967) (see Excursus) also applies to pretest interviews. After all, 'interviews' are, according to their origin in the French term 'entrevue', arranged encounters for verbal exchange and understanding based on mutual expectations (see also Kvale und Brinkmann 2009, p. 1-2).

Excursus: The indexicality of expressions in communication and its methodical treatment in qualitative research

The discussion of the problem of the inevitable vagueness of communication originates from Garfinkel's (1984/1967) discussion of the indexicality of expressions as a "constitutive moment of communication" (Przyborski and Wohlrab-Sahr 2008, p. 29; own translation). According to Garfinkel's ethnomethodological approach, expressions are potentially ambiguous references to meanings that are best understood in their context of origin. Thus, intersubjective understanding (Fremdverstehen) of meaning requires the consideration of these origins and contexts of expressions. In other words, the less familiar I am with another person's point of view, background and life-world, the more difficult it is to interpret his or her utterances 'correctly'.

The various approaches in the social sciences subscribe to different ways of dealing with this vagueness (Przyborski and Wohlrab-Sahr 2008: 28-31). Standardised procedures try to neutralise the indexicality of expressions (i.e. their potentially unclear reference) by attempting to standardise the semantic content. In practice, standardisation should ensure that all participants within an artificial-scientific context (i.e. the standardised situation, procedure, and contents of data collection) understand formulations of questions and answers in the same way. This is the precondition for capturing responses in a valid way and for the intersubjective comprehension of findings.

${ }^{6}$ https://www.gesis.org/en/services/study-planning/cognitive-pretesting/ (Access: 02.06.2020) 
In contrast, qualitative-reconstructive approaches recognize that expressions (within everyday frames of interpretation) always refer to everyday meanings that are specific for the very context of their articulation. Social scientists can only reconstruct these meanings (within scientific-theoretical frames of interpretation) in a valid and appropriate way if the original context of expressions is preserved during data collection. Ideally, the very context that is unfolded by the participants themselves constitutes the background against which expressions are interpreted. This is the context, in which expressions originally 'make sense'; and it is important to interpret their meanings within this original frame of reference.

Standardised research predefines the context of collecting responses. According to its programme it eliminates the chances and risks of achieving an embedded understanding of expressions and 'answers'. In contrast, qualitative procedures do not attempt to bypass the requirement of intersubjective understanding (Fremdverstehen) by artificially neutralising indexicality or by recontextualising expressions in a scientific perspective. Rather, qualitative-reconstructive approaches suggest various strategies to capture expressions within context, and thus preserving their indexical quality. In other words, in qualitative-reconstructive approaches, the inevitable process of intersubjective understanding is "methodically controlled in so far as the difference between the frames of interpretation of the researchers and those of the researched is systematically accounted for" (cf. Przyborski and Wohlrab-Sahr 2008, p. 31; own translation).

The qualitative interview can be characterised as "a fundamentally asymmetrical form of communication, which, however, is always co-produced and maintained by both participants, because, for example, during the interview situation both cannot help finding out what the other 'actually wants' (what his actual interests are, how he sees the situation, how he assesses his counterpart, etc.)" (Honer 2006, p. 95f., emphases in the original; own translation). In principle, this definition also applies to data collection in standardised face-to-face interviews as well as preparatory (cognitive) pretest interviews. However, in case of standardised interviews we need to extend the circle of involved persons to the many invisible third parties not present in the interview situation together with their claims to interpretation. ${ }^{7}$ From a qualitative-empirical perspective, in addition to cognitive aspects, pretest interviews function as a platform of social (i.e. collaborative and interactive) clarification of understanding and of communication processes. The goal is the standardisation of the meaning of questions and answers (Beatty 1995), and the establishment of processes and contents of communication on the basis of shared common sense and "stable interpretations" (Suchman and Jordan 1990, p. 240), which can then be constitutive of comprehensive validity claims.

The common features of interactive understanding and clarification of meaning - i.e. immediacy, situativity, interactivity, reactivity, and asymmetry - underline the conceptual similarity of (cognitive) pretest interviews and qualitative interviews. In a more recent textbook on the evaluation of Cognitive

\footnotetext{
${ }^{7}$ Suchman and Jordan (1990, p. 240) reflect on the complexity of the problem of validity of standardized surveys regarding data collection as well as secondary data analysis: "Validity is not assured simply by having interviewers repeat the same words across different respondents. In contrast to a thermometer or other instruments of measurement, an interview, no matter how standardized, remains fundamentally a linguistic and interactional event. (...) The problem of assessing the meaning of questions and responses extends beyond the interview situation. Even if questions and answers are interpreted in the way that their authors intended, it is by no means assured that other users of the data will share this understanding. Every researcher who employs survey data for descriptive or inferential statistics needs to know the sense in which the question was heard and answered to use the data legitimately. It follows that validity requires a mechanism to assure that all parties involved in the enterprise (including the author of the question, the interviewer, the respondent, the coder, and the analyst of the data) have a common understanding of what the question means and how the answer is to be taken. The only hope for such stable interpretations, and therefore validity, is active collaboration between all of these parties."
} 
Interviews, Willis (2015, p. $28 \mathrm{ff}$.) outlines his perception of kinship with qualitative and interpretive social research. However, there are differences, especially regarding focus and temporal horizon. (Cognitive) Pretest interviews that focus on comprehension first of all refer to spontaneous associations regarding topics, concepts, and formulations. Yet this is only a very small segment of the participants' related experience and knowledge and not sufficient to arrive at comprehensive and subjective sets of interpretations. Due to these limitations that neglect life-worldly representations and interpretations of experience, or at least asserts them only indirectly, Cognitive Interviews also have a 'narrow' temporal horizon; they focus mainly on the present.

This corresponds to standardised research that is typically interested in currently available interpretations that should be as unambiguously valid as possible. In contrast, qualitative interviews are characterised by a stronger orientation to the past. They try "to lure out of the other statements about something that is itself (in this way) not present in the interview situation; i.e.: to find out something specific through the other; usually something that is already in the past, that must therefore be re-presented through interviewing" (Honer 2006, p. 95; emphasis in the original; own translation). Despite these differences, even if the answers in Cognitive Interviews are pragmatically motivated and generally less comprehensive, they are always representations of knowledge and experience and for this very reason references to the past. Metaphorically speaking, in Cognitive Interviews only the roots of answers are shorter than in qualitative interviews.

Already the commonality of the intended intersubjective underlines the qualitative orientation of Cognitive Interviews: even though the focus is on mental processes, the desired clarification of interpretations refers to an essentially social encounter. Under the label of Furthermore, the following chapter moves the discussion further towards the development of a genuine Qualitative Pretest Interviews (QPI). It illustrates how suggestions from qualitative interview research can be instructive for refining the communication processes in pretest interviews that goes beyond improvements prompted by the cognitive turn. In particular, based on Willis' distinction between the alternative paradigms of thinking aloud and (verbal) probing we explore the potential of communication strategies proposed for the interactive clarification of meaning by two established and elaborated qualitative interview procedures (i.e. the Problem-centred Interview and the Discursive Interview).

\section{Building blocks of the Qualitative Pretest Interview: the communication strategies of the Problem-centred Interview and the Discursive Interview}

The paradigm of thinking aloud in Cognitive Interviews described by Willis (2005; Beatty and Willis 2007) has its origin in psychological laboratory analyses of short-term memory and information processing (Ericsson and Simon 1980). However, under artificial conditions of problem-solving thinking aloud has little in common with genuine qualitative social research (Konrad 2010). The alternative paradigm of probing goes back to a procedure that Willis (2005, p. 48) calls "intensive interview"; it is associated with early opinion research in the 1940s. During the CASM movement (Cognitive Aspects of Survey Methodology) mentioned in the introduction, the operation of probing followed a cognitive model of four analytically distinguishable stages (comprehension, retrieval, judgement, response) (Tourangeau 1984). Over time, the boundaries between thinking aloud and probing became increasingly blurred (Beatty and Willis 2007). On the one hand, very open formulations are used for intensive exploration and probing a; on the other hand, forms of verbal probing became part of thinking aloud. Recently, in view of the 'qualitative turn' Willis (2015, pp. 26-28) revised the relevance of cognitive-psychological assumptions for the practical implementation of the procedure: in view of other, at least additionally relevant theories, he describes 'cognitive interviewing' as a 'convenient label' and suggests that this term could be outdated. 
Regardless of this conceptual re-evaluation of the Cognitive Interview, the usefulness of the two analytically distinct paradigms for pretest interviewing (i.e. thinking aloud and probing) is undisputed when it comes to the improvement of standardised survey tools. Due to the recognition of the unavoidable indexicality of expressions (see Excursus above), qualitative social research does not consider contradictions and ambiguities in collected accounts as problematic, but rather expectable. Nevertheless, as the understanding of meaning is its primary concern, established qualitative interview methods suggest various communication strategies for the interactive clarification of ambiguities and joint interpretation. We argue that the development of questionnaires can benefit from making use of these suggestions for improving comprehension by means of routines that are similar to thinking-aloud and probing in Cognitive Interviews; they advocate the combination of stimulating self-generating accounts with conducting active explorations.

Within the diverse landscape of qualitative interviewing techniques rooted in the particular German methodology discourse, there are two approaches - i.e. the Problem-Centred Interview (PCl) and the Discursive Interview - that programmatically use comprehension-generating communication strategies. Both methods regard the interview situation not only as an opportunity for collecting accounts and information but also for directly negotiating implied meaning. ${ }^{8}$ Their particular features are instructive for the development of a genuinely Qualitative Pretest Interview (QPI).

\section{Communication Strategies of the Problem-Centred Interview}

The Problem-centred Interview (PCI) (Witzel 1982, 1989; Witzel and Reiter 2012; Reiter and Witzel 2019) conceptualises the situation of data collection as a research encounter for the discursivedialogical clarification of meanings. Researchers and respondents exchange views in everyday language on topics that interest the former scientifically and the latter from a practical perspective (Witzel and Reiter 2012, p. 18). The prior knowledge of researchers refers to (mostly explicit) research knowledge organised in a scientific perspective as well as to aspects of everyday life that can overlap with the respondents' practical knowledge and may initially remain implicit. For social researchers it is crucial that they disclose and explicate both strands of knowledge, i.e. everyday knowledge and research knowledge, as prior knowledge. This increases the chance for methodically controlled intersubjective understanding (see Excursus above). In addition and in view of the ambiguity and indexicality of expressions, the $\mathrm{PCl}$ proposes, to make good use of the distinct interpretive competence of the interview partners. They are not just respondents providing information that is collected and later analysed. The $\mathrm{PCl}$ recognises their participation, presence, and readiness to clarify meaning and involves them as temporary research assistants in the co-construction of interpretations and comprehension.

As the $\mathrm{PCl}$ unfolds, researchers develop initial pre-interpretations based on the ongoing account and invite interview partners to discuss them jointly and, if necessary, revise these pre-interpretations. Similar to the Cognitive Interview (Willis 2005), the PCl differentiates between two analytically distinct approaches and communication strategies of general exploration (1) and specific exploration (2) that should encourage more or less self-perpetuating accounts. Like in the Cognitive Interview, they are not used in separate phases or in succession but in combination according to the course of the conversation.

(1) Communication strategies of general exploration are dedicated to generating substance and 'material' in an open way. This includes narratives and extensive descriptions related to the key topics of the conversation. In this way, the respondent's point of view should be able to

\footnotetext{
${ }^{8}$ This is conceptually different from techniques like the narrative interview (Schütze 1983) whose "rules of engagement" (Jovchelovitch and Bauer 2000, p. 61) restrict direct interviewer involvement and postpone the process of interpretation and reconstruction until the encounter is concluded (and the respondents are absent).
} 
unfold gradually and mainly inductively. Initially, narration-generating opening questions break up the usual question-answer scheme of typical interviews. They provide an open space for responses and invite the interview partners to express themselves unreservedly and in accordance with their own relevancies regarding the topic. Interviewers prepare interview partners for this unusual situation: they hand over the role as driving force of this initial, highly asymmetrical interview phase; at the same time they keep involvement to a minimum and suspend their own opinion; they refrain from interrupting and instead restrict themselves to 'active listening' (i.e. they respond primarily non-verbally and affirmatively without interrupting the account). Further strategies of general probing encourage additional elaboration and structuring of the topic: detailing questions stimulate memory and produce specifications that can be illustrated with examples from experience; repeated thematic comparisons clarify and differentiate accounts; and ad-hoc questions encourage the filling of knowledge gaps and establish comparability. In terms of methodology, this set of PCI communication strategies of general exploration pursues the goal of eliciting contextualized expressions - i.e. expressions that can be interpreted from within their context of origin. They follow exactly the purpose of reducing the 'inevitable vagueness' of communication and promote intersubjective understanding (see Excursus above).

(2) The second set of $\mathrm{PCl}$ communication strategies of specific exploration fulfil a different purpose. They introduce a deductive moment into the conversation by identifying interconnections between statements, by clarifying possible misunderstandings and preinterpretations, and by validating attributions of meaning. In this way, the conversation becomes much more dialogic and symmetrical; and the stronger involvement of the interviewers reflects their effort to engage in 'active understanding' what is being said. Experience shows that well-prepared interview partners appreciate these dialogical elements of clarification; they feel taken seriously by the active negotiation and appropriation of their contributions as research participants. Like paraphrasing in the Cognitive Interview, mirroring is a form of specific exploration in PCls that contributes to the communicative validation of pre-interpretations. Interviewers summarise and rephrase statements of the participants, and in this way, put their re-contextualised interpretations of what has been said up for discussion. Comprehension questions follow up on statements and ideas and are used to clarify evasive, hidden, and contradictory answers in an unobtrusive manner. The communication strategy of confrontation finally intensifies this aspect by directly addressing inconsistencies and contradictions in the statements. The Discursive Interview described below exaggerates and methodologically intensifies this confrontational aspect for clarifying and consolidating controversial, contradictory, or alternative interpretations.

\section{$\mathrm{PCl}$ communication strategies and the Qualitative Pretest Interview}

The $\mathrm{PCl}$ communication strategies of general and specific exploration invite the interview partners to develop their points of view openly, to modify them and to defend them against possible misunderstandings on behalf of the interviewers. The aim is the joint consolidation of interpretations and the increasing of their validity. This interactive (i.e. social) clarification of assigned meaning is a first common feature of problem-centred and cognitive interviewing. Yet the programme of the $\mathrm{PCl}$ differentiates this aspect and related dynamics, which can be instructive for conducting QPIs.

Despite their completely different contexts of application, a second affinity exists between the $\mathrm{PCl}$ and the Cognitive Interview when we directly compare communication strategies of general exploration with the technique of thinking-aloud, on the one side, and communication strategies of specific exploration and probing techniques on the other. Both interview techniques use open strategies (i.e. general exploration and thinking aloud) to stimulate self-perpetuating accounts that produce a preliminary knowledge base, which is relatively little pre-structured by interviewer interests. This 
knowledge is then subjected to a process of specification and elaboration with the help of the more focussed strategies (i.e. specific exploration and probing). Both aspects are equally demanding in their methodological and practical implementation. Especially regarding the aspect of thinking aloud the development of QPIs could benefit from PCl strategies for stimulating open accounts. The consideration of these more elaborate techniques could altogether lead to a rehabilitation of open communication strategies in questionnaire development such as the very thinking-aloud, which, however, seems to have lost some importance in the more recent literature on Cognitive Interviews (Willis 2015, p. 36).

A third commonality, which established techniques reflect methodically, is the transition between roles that interviewers undertake during the conversation. For instance, the transition between active listening and active understanding that is fundamental to $\mathrm{PCl}$ communication is not discussed in Cognitive Interviews, although it is implied in alternating between thinking-aloud and probing. Thinking-aloud emphasises the thoughts, considerations, and conclusions that participants articulate independently. The activities of the interviewer are initially limited to maintaining the flow of thoughts of the participants; interventions of actively clarifying comprehension are not part of this technique. The transition to probing involves a shift from one-sided to more dialogical communication where questions and answers interlock directly for the purpose of improving comprehension. The QPI can benefit from the methodological foundations of $\mathrm{PCl}$ communication strategies and their suggestions to handle this complex and changeable interwovenness of questions and responses.

\section{Types of questions and stimuli in Discursive Interviews}

The Discursive Interview is another elaborated technique that combines different modes of asking and providing stimuli for a discursive-dialogical clarification of comprehension. Here, contradictions are addressed much more persistently than in the $\mathrm{PCl}$, and the particular way of using direct but methodically controlled confrontations could be exemplary for QPIs. The Discursive Interview was developed by Ullrich $(1999,2019)$ as a form of semi-structured interview for the analysis of interpretive patterns based on individual accounts. In practice, Discursive Interviews evoke and collect concrete realisations of socially rooted patterns of interpretation by (implicitly or explicitly) requesting from interview participants to provide justifications together with their responses. For example, during the conversation interviewers may refer to hypothetical situations or scenarios, use leading questions, or deliberately confront respondents with alternative or socially undesirable perspectives on sensitive topics. Finally, to obtain opinions and justifications about aspects of particular interest (for the researcher), Discursive Interviews make use of communication strategies of (internal and external) confrontation and polarisation (Ullrich 2019, p. 90-91). Within the framework of QPIs, these two techniques can supplement the range of probing tools provided in the Cognitive Interview with variants of 'confrontative probing' that go beyond $\mathrm{PCl}$ communication strategies of specific exploration.

(1) Internal confrontation questions are similar to confrontations in PCls; they refer exclusively to the conversation's immanent contents as offered by the respondents themselves. Interviewers can use these questions to confront participants with contradictions or inconsistencies and invite them to explain and resolve them. External confrontation questions introduce contentrelated topics and views that are of theoretical relevance but would not have been addressed by the interview partners themselves. This may involve alternative views and attitudes that contradict the situation definitions and action orientations expressed in the interview.

(2) Polarisations further exaggerate the idea behind external confrontations without direct reference to the content of the conversation. Interviewers confront the participants successively and flexibly with contrary opinions and ask them to comment on them. Thus, 
polarisations systematically expand the range of (alternative) opinions and collect the interview partner's reactions to them.

From a methodological point of view, the Discursive Interview shares with the $\mathrm{PCl}$ and other qualitative interview techniques the emphasis on active listening. Yet the process of active understanding, which is also central to the $\mathrm{PCl}$, can be even more accentuated here: in this variation of discursive processes of communication, interviewers explicitly highlight contradictions and alternative points of view in the sense of provocative explorations. At the same time, interviewers dominate the interaction by assuming a strongly controlling role; they consciously interrupt the conversation again and again and ask for opinions and justifications. Despite their dialogical orientation, Discursive Interviews are strongly asymmetrical. While it is important that the participants introduce their very own relevancies, the conversation is altogether far less open than the thinking-aloud procedure in Cognitive Interviews. In Discursive Interviews, the assertions of the participants are usually reactive and have the character of justifications (regarding differences of opinion). Similar to probing in Cognitive Interviews, participants in the Discursive Interview are guided by the interviewer's questions. However, the aim is not a joint reconstruction of cognitive steps or the generation of common understanding. Different from the $\mathrm{PCl}$, in Discursive Interviews the validation of interpretations (i.e. ecological validity) is not part of the actual interview conversation but postponed until after the encounter.

\section{DI communication strategies and the Qualitative Pretest Interview}

The communication strategies of neither the PCI nor the Discursive Interview were developed for testing the comprehension and interpretation of formulations in questionnaires. Yet despite their original field of application in qualitative social research, they can be instructive for the differentiation of probing procedures for the active clarification of meaning in QPIs.

External confrontations and polarisations can be particularly relevant in the context of QPIs: they open up the process of social clarification of interpretations by extending the discussion beyond the topics and relevancies introduced by the participants. In this way, they offer the possibility to introduce views and contradictions into the conversation that are not already part of the participants' universe of interpretation. Regarding the epistemological question of intersubjective understanding (Fremdverstehen) in QPIs, this means that external confrontations and polarisations directly and deductively introduce aspects of the researcher's framework of interpretation into the conversation. In this way, interviewers may address topics that are unfamiliar to the participants. They can even confront participants directly with the (by the researcher) intended meaning of formulated questions, provided that this intention can be communicated in appropriate everyday language. This form of proactive clarification of comprehension is particularly important for QPIs since the entire process of producing shared common sense understanding is pre-structured (in terms of purpose and contents); it is thus characterised by an altogether very limited degree of openness in the sense of qualitativeempirical research. In this situation, the methodical control of intersubjective understanding especially the identification and reconstruction of interpretations that can genuinely be attributed to either of the participants - will only succeed if related prior knowledge of researchers is systematically disclosed. Social research that operates based on a 'shadow methodology' (Kelle 2006, p. 296) by utilising common sense heuristics of everyday knowledge without reflecting them compromises the validity of findings. To avoid this problem, it is essential to indicate those prior knowledge shares of the researchers that overlap or could overlap with the everyday knowledge of the participants.

Persistent confrontation and polarisation are unusual in everyday communication. In case these strategies are used in the sense of the Discursive Interview it is necessary to brief participants of QPIs in a comprehensive way and to prepare and train interviewers for this extraordinary research encounter (Ullrich 2019, p. 89). For reasons of research ethics and in order to avoid irritation, 
participants need to be informed about the purpose and necessity of discussing contradictory aspects in QPIs. Their purpose is solely the joint identification of the appropriate, comprehensible and, in this sense, valid wording of questions. In terms of interview interaction, participants should be able to distinguish clearly between the levels of content and relationship: on the one hand, they must be able to separate controversial content from the person of the interviewer; on the other hand, they need to make sure that contradiction and apparent disagreement do not lead to unintended conflicts. Tricky interaction like this requires interviewers to be equipped with the appropriate communication skills. They need to be prepared to deal with alternative perspectives, insinuations of meaning and provocations in a way that the situation, despite its asymmetrical orientation, does not resemble an interrogation. This includes the appropriate briefing of the participants, the creation and maintenance of a trusting atmosphere, and the careful and flexible handling of the dynamics of difficult communication situations.

\section{Summary and conclusion}

The discussion about the degree of openness of the interaction between interviewers and interview partners has existed since at least the 1940s (Beatty 1995); more than 75 years after Lazarsfeld's (1944) first conciliatory intervention (e.g. West et al. 2018) it is still ongoing. Both parties involved in this debate provide reasonable arguments that are highly relevant for interview practice. The proponents of a strong standardisation on the one side emphasise the necessity of using an efficient and coherent protocol of data collection to generate adequate data for the analysis of statistical distributions. Advocates of open interviewing on the other side argue that the validity of the answers of participants depends essentially on a shared understanding of questions. They consider the possibility of reflecting on this understanding and clarifying it in the interview interaction a key element in reducing bias and error in surveys (Suchman and Jordan 1990). At the same time, more intensive interaction implies the danger of interviewer influence and thus the distortion of answers. Ongoing comparative research into the techniques of "conversational" and "standardised" interviews (e.g. Schober and Conrad 1997) sheds light on the trade-off between the two main sources of measurement error - i.e. wrong understanding of the question by the respondents and distorted answers due to the influence of the interviewer.

One area, in which the use of open interviewing techniques does not cause much controversy, is questionnaire development. It is possible to increase the validity of answers by preponing the open exchange about the meaning of questions and moving it from the primary survey to the process of questionnaire development. The above-mentioned "cognitive turn" in survey research in the 1980s resulted in a systematisation of open pretest techniques, especially through the development of methods that are now subsumed under the label of "Cognitive Interviews" (Willis 2005, 2015). These methods were developed to identify and, ideally, remedy problems in the respondents' understanding already in the process of designing the wording of questions.

This paper discusses the extent to which these - obviously highly successful - approaches can be further developed by focusing the methodological reflection on the social process of generating comprehension between pretest interviewers and respondents. We refer to the concept of intersubjective understanding (Fremdverstehen), which is central to all processes of direct communication including the negotiation of the meaning of questions or formulations in the pretest interview. We discuss to what extent suggestions of established, qualitative methods of empirical social research could be included in an integrated approach to conducting such interviews. To distinguish it from the practice of cognitive interviewing, we call the alternative approach 'Qualitative Pretest Interview' (QPI). Especially borrowings from the communication strategies of the Problem- 
centred Interview (Witzel and Reiter 2012) and the Discursive Interview (Ullrich 2019) seem suitable for developing this procedure.

A first review of these two interview methods and their possible contribution to further developing Cognitive Interviews in the direction of QPIs results in a few preliminary conclusions. First, it makes sense to conceptualise pretest situations as research encounters with the purpose of controlled intersubjective understanding. Once we recognise the clarification of comprehension and meaning as a social process and interaction, the consideration of basic principles of qualitative-reconstructive social research is essential for the preparation and implementation of standardised surveys and their validity. Especially in standardised procedures, it is impossible to overcome completely the problem of the 'inevitable vagueness' of communication. The goal is rather to arrive at a level of standardisation that does not attempt to eliminate the indexicality of expressions, which would technically be a requirement for the operation of 'measurement'.

Further research should therefore try to find out: (a) how to approximate the two different frames of interpretation of everyday life and social science; and (b) how to 'artificialize' and defamiliarise the frame of reference of participants in QPIs in a way that they are temporarily able to suspend their usual life-worldly context and everyday communication frameworks. The communication strategies of the $\mathrm{PCl}$ and the Discursive Interview presented here can be instructive despite their different contexts of origin and application. They are solidly anchored in interpretive methodology and complement the two central strategies of thinking-aloud and active probing in Cognitive Interviews with differentiated proposals for applying them within an extended reflexive and qualitative approach. Finally, the discussion indicates that conducting QPIs requires comprehensive competences on the part of the interviewers.

Conceptual conclusions like these are only a first step in assessing the potential of pretest interviews that subscribe to the tradition of qualitative research. In addition, their practical suitability still needs to be approved. First, regarding the concrete application researchers need to translate and communicate their ideas and find out whether interviewers can actually handle them in the research communication. In the meantime, first practical experiences were gathered in the frame of a research project and a university seminar about qualitative pretesting. They indicate that QPIs have many advantages over classical forms of cognitive interviewing when the goal is indeed intersubjective understanding and the clarification of how the wording of questions is appreciated (Bethmann et al., WIP). The task of pretesting standardised instruments of data collection with QPIs is at the intersection of quantitative and qualitative research; and only people that are familiar with both approaches will really be able to accomplish it. In fact, this equally applies to Cognitive Interviews, which need to be conducted by appropriately trained interviewers. Altogether, this challenge of qualitative pretesting underlines the benefits of a stronger integration of empirical research methods in education and training.

Furthermore, in order to foster the benefits of QPIs, or Cognitive Interviews as it were, in many cases project managers as well as funding bodies probably still need to be made aware of the advantages of open pretesting approaches in order to have the necessary funds and resources earmarked in grant proposals and budgeting of research projects. While open pretest procedures are expensive and resource intensive these expenditures are necessary to gain the full benefit for quality improvements in questionnaire design (cf. Willis 2015). Or as Sudman and Bradburn put it - bluntly - already in 1982 (p. 283): "It is even more important for researchers with limited resources to pilot-test their questionnaires before spending all their money. If you do not have the resources to pilot-test your questionnaire, don't do the study." The quality of surveys will certainly improve considerably from establishing any kind of open pretest procedure as the norm within standardised instrument development. 
Finally, even open forms of pretests will always have their limitations. Even the most elaborate procedure will not result in question wordings that produce equally valid answers for all different, heterogeneous groups of respondents. Conducting pretests with a variety of different types of respondents seems indicated. Still there will be cases where we are only able to find that some respondents may understand a specific question wording, while others do not. Standardisation across all groups of respondents will not be possible at all in some cases, and even open pretest procedures such as the proposed QPI will not be able to resolve these contradictions. Nevertheless, they can provide a nuanced basis for identifying group-differences in the comprehension of questions and for recognising the fundamental necessity of reflecting the concepts in the survey. Sometimes, QPIs might even be instrumental in determining that the study would benefit from an altogether more open approach to interviewing (e.g. Conversational Interviewing, cf. Schober and Conrad 1997).

\section{References}

Beatty, P. (1995). Understanding the standardized/non-standardized interviewing controversy. Journal of Official Statistics 11, 147-160.

Beatty, P., \& Willis, G. B. (2007). Research synthesis: The practice of cognitive interviewing. Public Opinion Quarterly 71, 287-311.

Bethmann, A., Buschle, C., \& Reiter, H. (2019). Kognitiv oder qualitativ? Pretest-Interviews in der Fragebogenentwicklung. In N. Menold, \& T. Wolbring (Ed.), Qualitätssicherung sozialwissenschaftlicher Erhebungsinstrumente (S. 159-193). Wiesbaden: Springer VS.

Bethmann, A., Buschle, C., \& Reiter, H. (WIP). Questioannaire Development using Qualitative Pretest Interviews: Examples from SHARE (Working Title).

Bradburn, N. M., Sudman, S., \& Wansink, B. (2004). Asking questions: The definitive guide to questionnaire design - For market research, political polls, and social and health questionnaires (2., überarb. Aufl.). Hoboken: Wiley.Chepp, V., \& Gray, C. (2014). Foundations and new directions. In K. Miller, S. Willson, V. Chepp, \& J.L. Padilla (Ed.), Cognitive interviewing methodology (S. 7-14). Hoboken: Wiley.

Collins, D. (2015a). Cognitive interviewing practice. London: SAGE.

Collins, D. (2015b). Cognitive interviewing: origin, purpose and limitations. In D. Collins, (Ed.), Cognitive interviewing practice (S. 3-27). London: SAGE.

Collins, D. (2003). Pretesting Survey Instruments: An Overview of Cognitive Methods. Quality of life research 12, 229-38.

Conrad, F., \& Blair, J. (2009). Sources of Error in Cognitive Interviews. Public Opinion Quarterly 73, 3255.

Ericsson, K. A., \& Simon, H. A. (1980). Verbal reports as data. Psychological Review 87, 215-251.

Faulbaum, F., Prüfer, P., \& Rexroth, M. (2009). Was ist eine gute Frage? Die systematische Evaluation der Fragenqualität. Wiesbaden: VS Verlag.

Garfinkel, H. (1984/1967). Studies in ethnomethodology. Cambridge: Polity Press.

Gobo, G., \& Mauceri, S. (2014). Constructing survey data. An interactional approach. London: SAGE.

Gray, M. (2015). Conducting cognitive interviews. In D. Collins (Ed.), Cognitive interviewing practice (S. 126-141). London: Sage. 
Groves, R. M., Fowler, Jr., F. J., Couper, M. P., Lepkowski, J. M., Singer, E., \& Tourangeau, R. (2009). Survey Methodology (2. Aufl.). Hoboken: Wiley.

Honer, A. (2006). Interview. In R. Bohnsack, W. Marotzki, \& M. Meuser (Ed.), Hauptbegriffe qualitativer Sozialforschung (S. 94-99). Opladen: Barbara Budrich.

Jovchelovitch, S., \& Bauer, M. (2000) Narrative Interviewing. In M. Bauer, \& G. Gaskell (eds.) Qualitative researching with text, image and sound. London: Sage. 57-74.

Kelle, U. (2006). Combining qualitative and quantitative methods in research practice: purposes and advantages. Qualitative Research in Psychology, 3, 293-311.

Kelle, U., Langfeldt, \& Metje, B. (2019). Qualitätssicherung von Einstellungsskalen mit Hilfe qualitativer Methoden und von "Mixed-Methods-Designs" - die Messung religiöser Überzeugungen. In N. Menold, \& T. Wolbring (Ed.), Qualitätssicherung sozialwissenschaftlicher Erhebungsinstrumente (S. 225-257). Wiesbaden: Springer VS.

Kohli, M. (1978). „Offenes" und „geschlossenes“ Interview: Neue Argumente zu einer alten Kontroverse. Soziale Welt 29, 1-25.

Konrad, K. (2010). Lautes Denken. In G. Mey, \& K. Mruck (Ed.), Handbuch qualitative Forschung in der Psychologie (S. 476-490). Wiesbaden: VS Verlag.

Lazarsfeld, P. F. (1944). The controversy over detailed interviews-an offer for negotiation. Public Opinion Quarterly 8(1), 38-60.

Lenzner, T., Neuert, C., \& Otto, W. (2016). Cognitive Pretesting. GESIS Survey Guidelines. Mannheim, Germany: GESIS - Leibniz Institute for the Social Sciences. doi: 10.15465/gesis-sg_en_010

Miller, K., Willson, S., Chepp, V., \& Padilla, J. L. (2014). Cognitive interviewing methodology. Hoboken: Wiley.

Pan, Y., Wake, V., Chan, G., \& Willis, G. B. (2014). A comparative study of English and Chinese cognitive interviews. Präsentiert beim Comparative Survey Design and Implementation Workshop, Bethesda, MD.

Platt, J. (2001). The history of the interview. In J. F. Gubrium, \& J. A. Holstein (Ed.), Handbook of interview research. Context und method (S. 33-54). Thousand Oaks: SAGE.

Ploder, A. (2018). Geschichte Qualitativer und Interpretativer Forschung in der deutschsprachigen Soziologie nach 1945. In S. Moebius, \& A. Ploder (Ed.), Handbuch Geschichte der deutschsprachigen Soziologie. Band 1: Geschichte der Soziologie im deutschsprachigen Raum (S. 735-760). Wiesbaden: Springer.

Porst, R. (2014). Fragebogen. Ein Arbeitsbuch (4. Aufl.). Wiesbaden: VS Verlag.

Presser, S., Couper, M. P., Lessler, J. T., Martin, E., Martin, J., Rothgeb, J. M., \& Singer, E. (2004). Methods for Testing and Evaluating Survey Questions. Public Opinion Quarterly 68, 109-130.

Prüfer, P., \& Rexroth, M. (2000). Zwei - Phasen - Pretesting. ZUMA-Arbeitsbericht 2000/08. https://www.gesis.org/fileadmin/upload/forschung/publikationen/gesis_reihen/zuzu_arbeits berichte/00_08.pdf. Zugegriffen: 19. März 2018.

Prüfer, P., \& Rexroth, M. (2005). Kognitive Interviews. ZUMA How-to-Reihe, Nr. 15. https://www.gesis.org/fileadmin/upload/forschung/publikationen/gesis_reihen/hohow/How _to15PP_MR.pdf. Zugegriffen: 19. März 2018. 
Przyborski, A., \& Wohlrab-Sahr, M. (2008). Qualitative Sozialforschung. Ein Arbeitsbuch. München: Oldenbourg Verlag.

Reiter, H., \& Witzel, A. (2019). Problem-centred interview. In P. A. Atkinson, S. Delamont, A. Cernat, J. W. Sakshaug, \& R. A. Williams (Ed.), SAGE Research Methods: An Encyclopedia. https://methods.sagepub.com/foundations/problem-centred-interview.

Schnell, R. (2012). Survey-Interviews. Wiesbaden: VS Verlag.

Schober, M. F., \& Conrad, F. G. (1997). Does conversational interviewing reduce survey measurement error? Public Opinion Quarterly 61, 576-602.

Schütze, F. (1983). Biographieforschung und narratives Interview. Neue Praxis 3, 283-293.

Suchman, L., \& Jordan, B. (1990). Interactional troubles in face-to-face survey interviews. Journal of the American Statistical Association 85, 232-241.

Sudman, S., \& Bradburn, N. M. (1982). Asking questions. Hoboken: Wiley.

Tourangeau, R., Rips, L. J., \& Rasinski, K. (2000). The Psychology of Survey Response. Cambridge: University Press.

Tourangeau, R. (1984). Cognitive sciences and survey methods. In T. B. Jabine, M. L. Straf, J. M. Tanur, \& R. Tourangeau (Ed.), Cognitive Aspects of Survey Methodology: Building a Bridge Between the Disciplines (S. 73-100). Washington, D.C.: National Academy Press.

Ullrich, C. G. (1999). Deutungsmusteranalyse und diskursives Interview. Zeitschrift für Soziologie 28, 429-447.

Ullrich, C.G. (2019): Das discursive Interview. Methodische und methodologische Grundlagen. Wiesbaden: Springer.

Weischer, C. (2018). Quantifizierende Sozialforschung nach 1945. In S. Moebius, \& A. Ploder (Ed.), Handbuch Geschichte der deutschsprachigen Soziologie. Band 1: Geschichte der Soziologie im deutschsprachigen Raum (S. 721-733). Wiesbaden: Springer.

West, B. T., Conrad, F. G., Kreuter, F., \& Mittereder, F. (2018). Can conversational interviewing improve survey response quality without increasing interviewer effects? Journal of the Royal Statistical Society - Series A: Statistics in Society 181(1), 181-203.

Willis, G. B. (2005). Cognitive interviewing. A tool for improving questionnaire design. Thousand Oaks: SAGE.

Willis, G. B., \& Artino, A. R., Jr (2013). What Do Our Respondents Think We're Asking? Using Cognitive Interviewing to Improve Medical Education Surveys. Journal of graduate medical education, 5(3), 353-356.

Willis, G. B. (2014). Foreword. In K. Miller, S. Willson, V. Chepp, \& J. L. Padilla (Ed.), Cognitive interviewing methodology (S. xiii-xiv). Hoboken: Wiley.

Willis, G. B. (2015). Analysis of the cognitive interview in questionnaire design. Oxford: University Press.

Willis, G. B. (2017). Cognitive Interviewing in Survey Design: State of the Science and Future Directions. In D. L. Vannette, \& J. K. Krosnick (Ed.), The Palgrave Handbook of Survey Research (S. 103107). London: Palgrave Macmillan. 
Witzel, A. (1982). Verfahren der qualitativen Sozialforschung. Überblick und Alternativen. Frankfurt/New York: Campus Verlag.

Witzel, A. (1989). Das problemzentrierte Interview. In G. Jüttemann (Ed.), Qualitative Forschung in der Psychologie. Grundfragen, Verfahrensweisen, Anwendungsfelder (S. 227-255). Heidelberg: Asanger Verlag.

Witzel, A., \& Reiter H. (2012). The problem-centred interview. Principles and practice. London: SAGE.

Wolf, C., Joye, D., Smith, T. W., \& Fu, Y. (Ed.). (2016). The SAGE Handbook of Survey Methodology. Thousand Oaks: SAGE. 